\title{
Design Dan Implementasi Wireless Sensor Network Pada Prototype Pendeteksian Material Galodo
}

\author{
Era Madona ${ }^{1}$, Muhammad Irmansyah $^{2 *}$, Yulastri $^{3}$, Anggara Nasution $^{4}$ \\ ${ }^{1234}$ Jurusan Teknik Elektro Politeknik Negeri Padang \\ emadona38@gmail.com \\ Kampus Politeknik Negeri Padang, Limau Manis Padang
}

\begin{abstract}
Flash flood (debris flow) or people of Padang called "galodo" is one disaster that could threaten any time, especially at plateau with high rainfall. This study is an attempt to design prototype which is implemented to detect the content of the existing material in river flows due to "Galodo". This research design and implement the wireless sensor network to transmit information or sensor output data and data receivers on prototype of "Galodo" material detection with laboratory testing scale. This system consist of a transmitter device that includes a sound sensor, Arduino Uno, and XBee S2, and a receiver that includes the XBee S2 and raspberry Pi as a database server. Data in data server are expected can distinguish the water in" Galodo" bring small material such as sand or larger or just contain of water. The information obtained display in graphic on the website to system data monitoring including time delay for sending data from transmitter to receiver.
\end{abstract}

Keywords: Database server, Wireless Sensor Network, Arduino Uno, XBee S2, Sound sensor

Abstrak - Banjir bandang (debris flow) atau yang dikenal dengan galodo oleh masyarakat kota Padang merupakan salah satu bencana yang dapat mengancam setiap saat terutama pada daerah dataran tinggi dengan curah hujan yang tinggi. Penelitian ini merupakan upaya untuk pembuatan prototype yang diimplementasikan untuk pendeteksian kandungan material yang ada pada aliran sungai akibat terjadinya galodo. Pada penelitian ini dirancang dan diimplementasikan wireless sensor network sebagai alat untuk pengiriman informasi atau data hasil pembacaan sensor dan penerima data pada prototype pendeteksian material galodo dengan pengujian masih skala laboratorium. Sistem ini akan terdiri atas perangkat transmiter yang mencakup sensor suara, Arduino Uno, dan XBee S2, dan receiver yang mencakup XBee S2 dan raspberry Pi sebagai database server. Data-data ini selanjutnya diolah sedemikian rupa sehingga diharapkan dapat membedakan apakah air yang ada pada galodo membawa material halus seperti pasir atau material yang lebih besar seperti kerikil atau hanya air saja. Informasi yang diperoleh ditampilkan dalam bentuk tampilan grafik pada web untuk memonitoring data yang dikirimkan oleh sistem termasuk waktu tunda sistem selama proses pengiriman data dari transmitter ke receiver

Kata kunci: Database server, Wireless Sensor Network, Arduino Uno, XBee2, Sensor suara

(C) 2019 Elektron Jurnal Ilmiah

\section{PENDAHULUAN}

Indonesia mengalami pergeseran musim yang luar biasa. Periode musim kemarau yang biasanya terjadi pada bulan April-September dan musim hujan pada bulan Oktober-Maret dengan musim pancaroba pada bulan Maret/April dan September/Oktober sekarang sudah tidak menentu. Kondisi cuaca yang mengalami perubahan ini juga berakibat pada bencana yang ditimbulkan seperti banjir sebagaimana yang terjadi di Padang dan Payakumbuh Sumatera Barat.

Banjir bandang adalah aliran massa sedimen (pasir, kerikil, batu dan air ) dalam satu unit dengan kecepatan tinggi. Terjadi karena keseimbangan statik antara gaya geser yang ditimbulkan oleh aliran lebih besar dari gaya geser massa sedimen yang menahan. Karena massa yang mengalir ini mempunyai percepatan maka ketinggian dan kecepatannya akan selalu bertambah, dan pada tingkat batas tertentu keadaan menjadi tidak stabil sehingga massa sedimen terangkat dengan cepat yang menimbulkan banjir bandang (Maryono A dalam Danoedoro, Projo, 2008).

Galodo atau banjir bandang telah melanda Batang Kuranji pada hari Selasa tanggal 24 Juli 2012 pukul 18.00 WIB. Daerah yang terkena bencana banjir bandang ini meliputi 19 Kelurahan dalam 7 kecamatan di Kota Padang (Padang Ekspres 28 Juli 2012). Pemantauan terhadap bencana alam yang sudah dilakukan kebanyakan bergantung kepada infrastruktur yang ada di sekitar tempat bencana, seperti ketersediaan daya listrik PLN dan jaringan komunikasi, sehingga pembangunan situs pemantauan bencana alam terbatasi oleh ketersediaan fasilitasfasilitas tersebut. Pemantauan terhadap banjir bandang biasanya dilakukan di hulu sungai yang jauh dari pemukiman yang tentunya juga jauh dari fasilitasfasilitas tersebut di atas. Oleh karena itu penggunaan jaringan sensor nirkabel (Wireless Sensor Network) merupakan solusi tepat (Maneesha V. Ramesh,2009; Wen-Zhan Song, Renjie Huang, Mingsen Xu, Behrooz 
A. Shirazi, Richard LaHusen,2010; Sunkpho, Jirapon Ootamakorn, Chaiwat, 2011).

Penelitian ini merancang dan mengimplementasikan wireless sensor network sebagai alat untuk pengiriman, router dan penerima data pada prototype pendeteksian material galodo. Data- data ini selanjutnya diolah dengan menggunakan sistem mikrokontroler arduino. Hasil pengolahan data akan disimpan ke dalam database MySQL Server. Datadata ini selanjutnya diolah sedemikian rupa sehingga diharapkan dapat membedakan apakah air yang ada pada galodo membawa material halus seperti pasir atau material yang lebih besar seperti kerikil atau hanya air saja.

Beberapa penelitian telah dilakukan terkait dengan monitoring untuk bencana banjir bandang atau galodo. Arattona dkk dalam penelitiannya menggunakan sensor-sensor seperti bandul atau pendulum, kawat bentangan melintasi kanal, sensor ultrasonic dan kamera CCD (M. Arattano and L. Marchi, 2007), instalasi sensor-sensor tersebut cukup memakan tempat serta rawan akan kerusakan ketika terjadi terjangan galodo dan tentu saja mahal karena perangkat yang digunakan banyak macamnya. Huang Chen Lee dkk merancang sebuah alat yang bernama INSIDER yang diletakkan pada aliran sungai, alat tersebut terdiri dari TI CC2420 RF transceiver sebagai alat pengiriman dan dilengkapi dengan beberapa sensor seperti sensor geophone, rainfall dan waterlevel serta kamera CCD. Data sensor kemudian dikirim ke server (Huang-Chen Lee, Amit Banerjee, Yao-Min Fang, Bing-Jean Lee, 2010).

Hasil penelitian menunjukkan pembacaan sensor cukup akurat dan proses komunikasi data antara INSIDER dan server mengalami permasalahan jika alat terendam oleh air.Untuk mengatasi hal tersebut Huang Chen Lee dkk menaikkan output power pada TI CC2420 sebesar $22 \mathrm{dbm}$ dan meletakkan alat pada aliran sungai yang agak dangkal dan kering serta melengkapi alat dengan flash memori untuk menyimpan informasi. Dalam penelitian ini prototype yang diusulkan menggunakan sensor suara untuk mendeteksi gelombang suara yang dihasilkan oleh air yang mengalir, data kemudian dikirim melalui komunikasi wireless dengan memanfaatkan protokol routing AODV dan kemampuan network self healing pada xbee (Datasheet Xbee S2, 2013), untuk menjaga kontinuitas informasi ke database server dan kemudian ditampilkan melalui website. Adapun keuntungan dari system yang diusulkan ini adalah biaya untuk perangkat dan perawatan yang tergolong rendah karena tidak membutuhkan infrastruktur untuk link komunikasi serta data yang tersimpan secara real time sehingga dapat dianalisa sesuai dengan kebutuhan.

\section{METODE PENELITIAN}

Pada bagian ini, dipaparkan pembahasan singkat mengenai perancangan alat dan implementasi sistem serta cara kerja sistem yang terdapat dalam garis besar perancangan sistem dan diikuti dengan penjelasan tentang perangkat keras (hardware) yang terdiri dari beberapa bagian yang berfungsi untuk mengolah data.Kemudian diikuti dengan perancangan perangkat lunak (software).

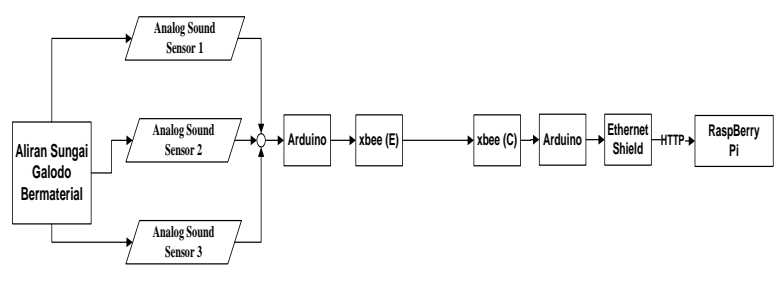

Gambar 2. Blok diagram sistem pendeteksi galodo

Proses dari diagram blok diatas dapat dijelaskan bahwa diagram ini terdiri dari beberapa bagian yaitu suara aliran sungai sebagai objek pemantauan (monitoring). Transmiter, terdiri atas sensor suara, XBee, dan arduino yang dihubungkan langsung dengan sumber tegangan.Receiver, terdiri atas Xbee, arduino, ethernet shield. Raspberry Pi Berfungsi sebagai PC Server untuk menyimpan data kedalam mysql menggunakan PHP untuk tampilan data ke website.Setelah data di terima oleh XBee Coordinator, data tersebut akan di tampilkan dan dibaca oleh Arduino, kemudian di kirim data melalui HTTP ke raspberry pi menggunakan modul Ethernet shield, dan terakhir data di Raspberry PI ini yang akan menampilkan data-data melalui website.

\section{A. Perancangan Hardware}

\section{Transmitter}

Pada bagian transmitter ini menggunakan 3 (tiga) sensor suara. Sensor-sensor itu akan diolah dengan mengunakan mikrokontroller ATmega2560 yangakan ditampilkan dalam bentuk serial, dimana data serial itu akan dikirim menggunakan wireless sensor network ke receiver.

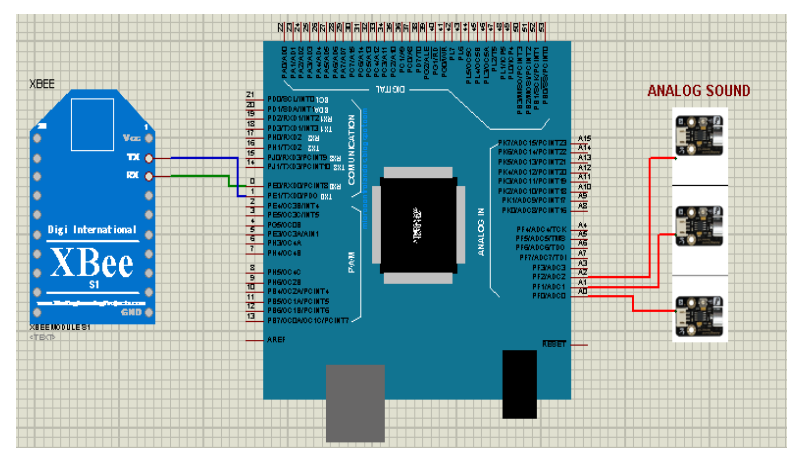

Gambar 3. Rancangan hardware transmitter 


\section{Receiver}

Pada bagian ini data yang telah dikirim transmitter melalui router akan diterima oleh receiver melalui wireless sensor network dalambentuk data serial. Pada receiver sendiri terdiridari arduino, Ethernet shield, Xbee, RTC danmodem router. Data yang telah diterima melaluiXBee, akan dikirim kembali ke raspberry piyang berfungsi sebagai server, pengiriman itusendiri menggunakan Ethernet shield, untuk itumembutuhkan modem internet router. Data yangdikirim akan ditambahkan tanggal dan jampengiriman oleh rangkaian RTC. Sehingga kita dapat membandingkan berapa delay data saat sampai ke server.

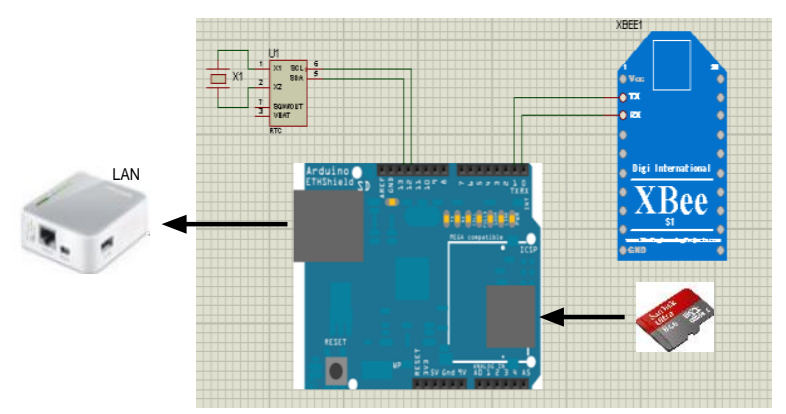

Gambar 4. Rancangan hardware transmitter

\section{B. Perancangan Software}

Untuk peracangan Software memiliki beberapa tahapan yaitu:

1. Instalasi OS

2. Instalasi Web Server

3. Instalasi Database Server

\section{HASIL DAN PEMBAHASAN}

Dari rancangan hardware transmitter dan receiver, dapat diimplementasikan pada alat dengan hasil yang diperoleh sebagai berikut:

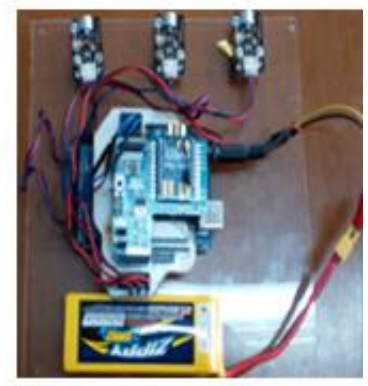

TRANSMITTER

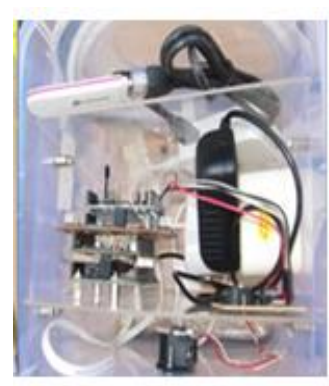

RECEIVER

Gambar 5. Hardware transmitter dan receiver

Dari tabel 1. dapat dilihat bahwa waktu pengiriman data dari transmitter ke receiver yang didapat mengalami kenaikan mengikuti kenaikan nilai jarak antar device. Berdasarkan hasil pengukuran dengan menggunakan stopwatch, didapatkan bahwa untuk jarak 200 meter sampai dengan 350 meter, waktu yang dibutuhkan untuk proses recovery network memiliki nilai minimum 6 detik dan delay maksimum sebesar 38 detik. Untuk jarak $375 \mathrm{~m}$ dari router ke coordinator komunikasi terputus dikarenakan jarak maximal yang diizinkan untuk pengiriman adalah 350 m. Percobaan di atas dapat dikaitkan dengan delay transmisi data, yaitu waktu yang dibutuhkan data untuk sampai dari transmiter menuju receiver. Dalam transmisi komunikasi dalam sebuah medium, ketika gelombang informasi merambat tentu akan membutuhkan waktu, waktu perambatan inilah yang membuat waktu kirim tidak sama dengan waktu terima. Dapat diambil kesimpulan bahwa semakin jauh jarak antar perangkat komunikasi yang digunakan, maka semakin lama waktu yang dibutuhkan informasi untuk sampai ke receiver. 
Delay pengiriman data dari coordinator ke server.

Tabel 2. Delay pengiriman data dari coordinator ke server

\begin{tabular}{|c|c|c|}
\hline Coordinator & Server & Delay \\
\hline hh:mm:ss & hh:mm:ss & s \\
\hline $8: 40: 25$ & $8: 41: 28$ & 63 \\
\hline $8: 40: 32$ & $8: 41: 35$ & 63 \\
\hline $8: 40: 35$ & $8: 41: 38$ & 63 \\
\hline $8: 40: 34$ & $8: 41: 37$ & 63 \\
\hline $8: 40: 37$ & $8: 41: 41$ & 64 \\
\hline $8: 40: 39$ & $8: 41: 43$ & 64 \\
\hline $8: 40: 41$ & $8: 41: 45$ & 64 \\
\hline $8: 40: 43$ & $8: 41: 48$ & 65 \\
\hline $8: 40: 45$ & $8: 41: 51$ & 66 \\
\hline \multirow[t]{2}{*}{$8: 40: 47$} & $8: 41: 53$ & 66 \\
\hline & Average & 64.1 \\
\hline
\end{tabular}

Dari tabel 2 dapat dilihat, pengujian dilakukan dengan mencatat waktu pengiriman data dari Coordinator ke server dengan rata-rata 64,1 second. Dengan selang waktu yang relatif kecil ini maka dapat disimpulkan bahwa data yang ditampilkan merupakan data update dan realtime.

\section{Pengujian Menggunakan Web Interface}

Pengujian sistem ini dilakukan dengan cara menguji fungsional sistem monitoring pendeteksi material galodo berbasis web. Hasil pengujian web interface dapat diperlihatkan pada tampilan web interface dan grafik pembacaan nilai adc masing-masing sensor dapat dilihat pada gambar 5 .

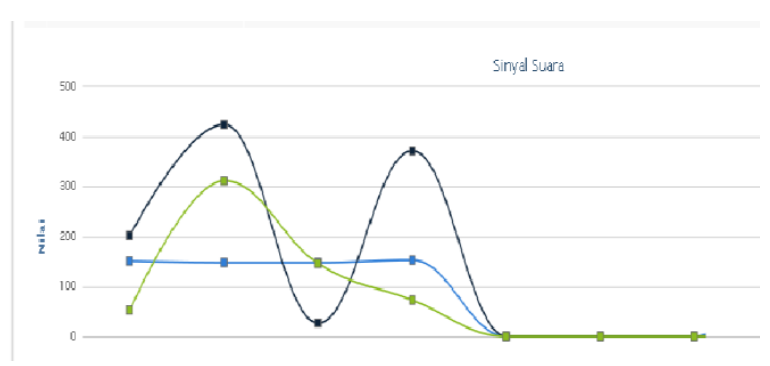

Berdasarkan gambar 5, masing-masing grafik mewakili satu sensor suara yang digunakan. Data nilai ADC untuk air tanpa material pasir dan kerikil sebesar 60-75, sedangkan nilai ADC untuk air dengan material pasir dan kerikil 95-120 yang merupakan range ratarata dari tiga sensor suara yang digunakan

\section{IV.KESIMPULAN}

Berdasarkan pada hasil perancangan,pengujian dan analisa yang dilakukan terhadap prototype alat pendeteksian galodo berbasis wsn yang dibangun, maka didapatkan jarak maksimum pengiriman data dari transmitter ke receiver adalah 350 meter dengan waktu tunda 35 detik. Sedangkan waktu tunda ratarata pengiriman data dari coordinator ke server adalah 64.1 second dengan data ADC 60-75 untuk air dengan tanpa material pasir dan 95-120 dengan material pasir dan kerikil.

\section{REFERENSI}

[1] Maryono A dalam Danoedoro, Projo (2008). Dampak Perubahan Penggunaan Lahan terhadap Respons Debit dan Bahaya Banjir, PUSPICS Fakultas Geografi Universitas Gadjah Mada, 19 - 26.

[2] Maneesha V. Ramesh (2009). Real-time Wireless Sensor Network for Landslide Detection, Proceeding The $3^{\text {rd }}$ International Conference on Sensor Technologies and Applications-ISBN :978-0-7695-3669-9, Athens, 18-23 June 2009.

[3] Sunkpho, Jirapon Ootamakorn, Chaiwat. 2011. Real-time flood monitoring and warning system. Songklanakarin Journal of Science and Technology Volume 33. Issue 2. Pages :227-235 2011

[4] Wen-Zhan Song, Renjie Huang, Mingsen $\mathrm{Xu}$, Behrooz A. Shirazi, Richard LaHusen (2010).Design and Deployment of Sensor Network for Real-Time High-Fidelity Volcano Monitoring ,IEEE TRANSACTIONS ON PARALLEL AND DISTRIBUTED SYSTEMS, VOL. 21, NO. 11, NOVEMBER 2010

[5] M. Arattano and L. Marchi. Systems and Sensors for Debrisflow Monitoring and Warning. Sensors 2008. 2007; 8: 24362452.

[6] Huang-Chen Lee, Amit Banerjee, Yao-Min Fang, Bing-Jean Lee And Chung-Ta King (2010). Design of aMultifunctionalWireless Sensorfor In-Situ Monitoring of Debris Flows. IEEE TRANSACTIONS ON INSTRUMENTATION AND MEASUREMENT, VOL. 59, NO. 11, NOVEMBER 2010

[7] Agung Priyanto, Widyawan, Sujoko. 2014. Observasi Aliran Sungai Untuk Perigatan Dini Banjir LAar Dingin Memanfaatkan Jaringan Sensor Nirkabel Platform IQRF. EJournal UNDIP Vol 16.No 1 (2014).

[8] Datasheet Xbee S2

Gambar 5. Tampilan web interface 